\title{
Mulheres na liderança: discurso, ideologia e poder
}

\section{Women in leadership positions: discourse, ideology and power}

\author{
Vicentina Ramires ${ }^{1}$ \\ Departamento de Letras da Universidade Federal Rural de Pernambuco \\ vicentinaramires@terra.com.br \\ Dina Ferreira \\ Programa de Pós-Graduação em Linguística Aplicada, Universidade Estadual do \\ Ceará/UECE \\ dinaferreira@terra.com.br
}

Resumo: Dominação, força e autoridade são conceitos ainda circunscritos ao universo masculino, e isso pode ser constatado principalmente nas relações de trabalho, mesmo naquelas em que as mulheres exerçam funções de liderança. Esse quadro também se materializa na academia, onde os sujeitos estão, hipoteticamente, mais atentos às diferentes posições ideológicas e às formas como se manifestam, e, por conseguinte, mais ou menos a elas refratários. O objetivo geral deste estudo é demonstrar como hierarquias de poder no mundo do trabalho baseadas em diferenças de sexo são ideologicamente construídas, de maneira a reforçarem as formas dicotômicas de relações de gêneros e como as próprias mulheres, atuando em culturas androcêntricas, podem contribuir para perpetuar atitudes sexistas. Com base nos Estudos Críticos de Discursos, procuramos: a) identificar os discursos que corroboram para construir ou desconstruir modelos de dominação nas relações de gênero;

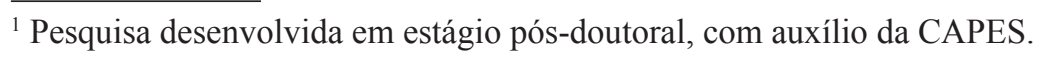


b) observar em que formações discursivas esses modelos se impõem e c) identificar em que medida procedimentos de discriminação são veiculados nos discursos proferidos pelas mulheres. Este estudo foi desenvolvido em duas instituições de ensino superior, analisando entrevistas e respostas aos questionários dirigidos a mulheres que ocupam posições de liderança. Observamos que, ao mesmo tempo que muitas mulheres reforçam a assimetria de gêneros existente entre posições de poder na sociedade, ao repetirem/confirmarem discursos, outras vão tomando consciência de seu espaço na sociedade e agem criticamente em defesa de direitos iguais entre homens e mulheres.

Palavras-chave: gênero; discurso; ideologia; poder.

Abstract: Domination, power and authority are still confined to male universe, and this can be found mainly in work relationships, even those in which women occupy leadership roles. This framework is materialized in academic communities, where subjects are hypothetically more attentive to the different ideological positions and how they are presented, and thus, more or less refractory to them. The aim of this study is to demonstrate that power hierarchies in the labor world based on sex differences are ideologically constructed in order to strengthen the dichotomous forms of gender relations. We also intend to analyze how women themselves, working in male-centered cultures, contribute to perpetuate sexist attitudes against themselves. Based on Critical Discourse Studies we seek to a) identify discourses that support to build or deconstruct models of dominance in gender relations; b) observe in which discursive formations such models are imposed and c) identify to what extent discrimination procedures are found in discourses made by women. This study was conducted in two universities, by analyzing interviews and responses to questionnaires sent to women in leadership positions. We note that, while many women reinforce the asymmetry of genres between positions of power in society, repeating/confirming discourses, others are aware of their place in society and act critically in defense of equal rights for men and women.

Keywords: gender; discourse; ideology; power.

Recebido em 10 de julho de 2016.

Aprovado em 10 de abril de 2017. 


\section{Introdução}

As transformações ocorridas na condição feminina ao longo das últimas décadas ainda não são suficientes para que as mulheres possam decidir sobre suas vidas, pois não exercem o poder em sua plenitude e, principalmente, não acumulam esse poder, quando o reproduzem, não para elas mesmas, mas para aqueles que de fato controlam o poder (COSTA, 2000).

Esse quadro pode parecer exagerado, em tempos de tecnologia avançada, em que se apresentam, sobretudo na mídia eletrônica e impressa, imagens de mulheres bem-sucedidas, firmes e decididas, responsáveis, muitas vezes, pelo correr do fluxo da economia em alguns centros urbanos. Entretanto, analisando a situação de um tempo mais remoto, em que a passividade da mulher e a sua submissão dentro do mundo doméstico, vivenciadas durante uma longa história de opressão, foram utilizadas para impor-lhe o pagamento de salários inferiores aos dos homens, com jornadas de trabalho excessivas e insalubres, percebe-se que esse quadro ainda hoje permanece, em grande medida (MACÊDO, 2003). A dominação, a força, a autoridade central estavam circunscritos ao universo masculino, e esse fato pode ser constatado na história mais recente, principalmente nas relações de trabalho, seja naquelas em que as mulheres exercem funções de liderança/comando/direção, seja naquelas em que se encontram subordinadas ao domínio masculino. Nas posições de liderança, por exemplo, as mulheres ainda deparam com "duplos discursos": elas têm que justificar constantemente sua presença e suas conquistas e ainda são avaliadas com diferentes normas, ou seja, simplificadamente, qualificações iguais atribuídas ao sexo masculino ou feminino não são avaliadas da mesma forma. Significativamente subrepresentadas nesses postos, as mulheres, por outro lado, têm expressiva representação em funções tais como vendedoras, domésticas, funcionárias e professoras.

Um relatório da Organização para Cooperação e Desenvolvimento Econômico divulgado no final de 2015 revela que o salário médio de uma mulher brasileira com nível superior corresponde a $62 \%$ da renda mensal de homens com a mesma escolaridade. Dos 42 países analisados pela Organização, o levantamento mostrou que o Brasil é o país com a maior diferença salarial entre cidadãos com diploma universitário em comparação àqueles com grau de instrução inferior. A desigualdade de 
gênero também se manifesta nesse quesito: $72 \%$ de homens que têm um diploma universitário ganham mais de duas vezes a média da renda nacional. Entre as mulheres, a taxa cai para $52 \% .^{2}$ A remuneração das mulheres com curso superior era, em média, $40 \%$ inferior à dos homens. ${ }^{3}$ Esses números causam estranheza quando se confirma que as mulheres brasileiras deixaram de ser minoria entre os doutores titulados no Brasil a partir do ano de 2004. Desde então, o número de mulheres tituladas tem sido superior ao de homens, atingindo o percentual de 51,5\% de doutoras no país, ${ }^{4}$ ou seja, essas estatísticas de desigualdade na remuneração não são explicadas pela escolaridade, visto que, nesse aspecto, elas ocupam posição de destaque.

Nos espaços políticos no Brasil, a divisão de gêneros consegue ser mais cruel. Em entrevista concedida à BBC Brasil, em 14 de maio de 2016, ao falar sobre a atitude do presidente em exercício no Brasil, à época, Michel Temer, em privilegiar homens brancos na composição de seu ministério, Jennifer Berdahl, professora da Universidade de British Columbia, no Canadá, ${ }^{5}$ critica veementemente essa decisão, ao afirmar que essa é "uma mensagem realmente má e perigosa que ele manda à população", pois desencoraja mulheres e minorias a buscar espaços na política brasileira. Apesar de concordar que as escolhas devam se basear em mérito, ela pondera que o mérito é igualmente distribuído entre gêneros e raças, e que, portanto, os percentuais de mulheres e minorias em posição de liderança deveriam seguir os do resto da população. Para ela, quando só são nomeados homens brancos, ou se acredita que só eles têm méritos, ou o sistema na verdade não é baseado no mérito. ${ }^{6}$

Levemos em conta que todo esse quadro descrito se materializa em comunidades acadêmicas, ou seja, em contextos de realização de

\footnotetext{
${ }^{2}$ Publicado originalmente na edição 878 de Carta Capital, com o título, "Injustiça de gênero". Novembro de 2015.

${ }^{3}$ Algumas características da inserção das mulheres no mercado de trabalho (Recife, Salvador, Belo Horizonte, Rio de Janeiro, São Paulo e Porto Alegre) 2003-2008.

${ }^{4}$ Doutores 2010: estudos da demografia da base técnico-científica brasileira - Brasília, DF: Centro de Gestão e Estudos Estratégicos, 2010.

${ }^{5} \mathrm{O}$ atual ministério do Canadá (em 2016) é considerado o mais diverso da história do país: há igual número de homens e mulheres, há ministros indígenas e membros de comunidades imigrantes.

${ }^{6}$ Disponível em: <http://www.bbc.com/portuguese/brasil/2016/05/160513entrevistap rofessoracanadajf_cc $>$. Acesso em: 16 maio 2016.
} 
linguagem em que os sujeitos estão, pelo menos hipoteticamente, mais atentos às diferentes posições ideológicas e como elas se manifestam, e, por conseguinte, mais ou menos a elas refratários a elas. Aparentemente e é isso que queremos analisar-, os discursos que circulam na sociedade em geral e reproduzem o modelo tradicional de divisão sexual do trabalho atravessam espaços considerados como de "produção de saber", a exemplo das universidades, públicas ou privadas.

Outro ponto que merece atenção é o fato de que, apesar de mais mulheres terem atingido maiores status em suas profissões, ainda há, em muitas culturas organizadas, sutis (e também manifestos) procedimentos de discriminação que têm, tacitamente (e, muitas vezes, explicitamente) a cumplicidade das mulheres.

De modo mais abrangente, é possível construir a hipótese de que essas mulheres - nas suas formas particulares de representar, de interagir, de situar e de se identificarem em diferentes práticas sociais - incorporam e reproduzem os discursos discriminatórios como explicação para as condições de vida e trabalho em que estão situadas, sugerindo que as ideologias implícitas nas práticas discursivas podem ser muito eficazes quando se tornam naturalizadas e atingem o status de senso comum. É nessa perspectiva que a análise crítica feminista de discursos pode dar conta dessa problemática, ao criticar discursos que contribuem para manter uma ordem social patriarcal, cujas relações de poder privilegiam homens e excluem mulheres como grupo social.

Tendo sido esses pontos rapidamente considerados, o objetivo geral deste estudo é demonstrar que hierarquias de poder no mundo do trabalho baseadas em diferenças de sexo são ideologicamente construídas, de forma a fazer perpetuar as formas dicotômicas de relações de gêneros. Paralelamente, sem simplificar a questão, pretendemos também analisar como as próprias mulheres, atuando em culturas androcêntricas, contribuem para perpetuar atitudes sexistas e práticas contra elas mesmas. Para tanto, com base nos estudos críticos dos discursos, procuraremos: a) identificar as formas discursivas (macro e microssemânticas) que corroboram para construir ou desconstruir esses modelos de dominação nas relações de gênero; b) observar em que formações discursivas (considerados gêneros, faixa etária, nível socioeconômico, formação educacional, entre outras variáveis) esses modelos se impõem e c) identificar em que medida procedimentos de discriminação são veiculados nos discursos proferidos pelas próprias mulheres. 


\section{Referencial teórico}

\subsection{Conceito(s) de gênero}

A literatura apresenta uma vasta fonte de pesquisa de autores/as que abordam o conceito de gênero como instrumento teórico e empírico para a análise das relações sociais. Um dos estudos feministas que trouxe novas perspectivas para os estudos de gênero foi o desenvolvido pela historiadora norte-americana Joan Scott, cujo célebre artigo Gênero: uma categoria útil de análise histórica (1995), publicado originalmente em 1986, tornou-se um clássico, por desconstruir a visão binária de que as distinções entre o feminino e o masculino não são fatos naturais (determinismo biológico), mas, ao contrário, são forjadas pelos indivíduos em sociedade e perpassadas pela cultura. Portanto, segundo Joan Scott (1995), gênero é categoria relacional, ou seja, abrange as relações sociais entre o feminino e o masculino, de forma que um gênero só adquire sentido na relação com o outro. Desse modo, o conceito de gênero se apresenta como um meio de distinguir a prática sexual (determinado pela natureza biológica do sexo feminino e masculino) dos papéis sociais (divisão sexual do trabalho, por exemplo), identidades e comportamentos opostos atribuídos aos homens e às mulheres na sociedade. As relações de gênero, assim como as de classe ou de etnia, são imbricadas pelo contexto social, cultural, político e econômico, ou seja, são construções históricas, portanto, multilineares e mutáveis. Em síntese:

Estabelecidos como um conjunto objetivo de referências, os conceitos de gênero estruturam a percepção e a organização concreta e simbólica de toda a vida social. Na medida em que essas referências estabelecem distribuições de poder (um controle ou um acesso diferencial aos recursos materiais e simbólicos), o gênero torna-se implicado na concepção e construção do próprio poder (SCOTT, 1995, p. 88).

O determinismo biológico, que embasa a discriminação entre gêneros, primordialmente, pode ser entendido como o conjunto de teorias segundo as quais a posição ocupada por diferentes grupos nas sociedades, ou comportamentos e variações das habilidades, capacidades, padrões cognitivos e sexualidade humana, derivam de limites ou privilégios inscritos na constituição biológica, ou seja, nos corpos sexuados 
(MACEDO, 2003). Essa noção fundamenta a ideia de que o poder pode ser distribuído de maneira desigual entre os sexos, cabendo às mulheres uma posição subalterna na organização da vida social, dado que elas são, nessa concepção, biologicamente inferiores aos homens. Assim é que o patriarcado concede direitos sexuais aos homens sobre as mulheres, sustentando-se sobre uma base material e simbólica, configurando-se por estruturas de poder hierárquicas e desiguais - presentes em todos os espaços - na sociedade, no estado, na cultura, na religião, e, assim, reproduzindo o binarismo do público-privado entre homens e mulheres, de forma a se garantir uma desejada "estabilidade" de todo um sistema baseado nessas diferenças, conforme assevera Scott (1995):

$\mathrm{O}$ gênero é uma das referências recorrentes pelas quais o poder político tem sido concebido, legitimado e criticado. Ele não apenas faz referência ao significado da oposição homem/mulher; ele também o estabelece. [...] Dessa maneira, a oposição binária e o processo social das relações de gênero tornam-se parte do próprio significado de poder; pôr em questão ou alterar qualquer de seus aspectos ameaça o sistema inteiro (SCOTT, 1995, p. 92).

Ao mesmo tempo, a ideologia liberal dominante faz crer que todas as mulheres são iguais, o que não pode ser verdade. Entretanto, essa noção faz as experiências parciais, de acordo com a classe social, orientação sexual, geografia, cor, serem universalmente compartilhadas, sem que se considerem as diferentes necessidades das mulheres, descaracterizando-as, portanto. Expressando um pensamento totalmente contrário a essa ideia, para Lazar (2005), duas importantes compreensões para ACD feminista são o reconhecimento das diferenças e diversidades entre mulheres (e homens) e a prevalência dos sutis funcionamentos discursivos do poder moderno em muitas sociedades.

Com essa mesma convicção, a filósofa norte-americana Judith Butler discorda de que só se poderia fazer uma teoria social sobre o gênero e que o sexo pertenceria ao corpo e à natureza. Para ela, "por mais que o sexo pareça intratável em termos biológicos, o gênero é culturalmente construído: consequentemente, não é nem o resultado causal do sexo nem tampouco tão aparentemente fixo como o sexo" (BUTLER, 2016, p. 26). Sem dúvida, não se pode negar que o feminismo é uma luta pelos direitos das mulheres, mas é preciso ter claro, segundo a própria 
filósofa tem defendido em toda a sua obra, que a questão de gênero é, principalmente, um questionamento da identidade e do princípio que rege sua lógica, isto é, um problema ontológico.

Assim que, como bem ressalta Butler (2016),

A complexidade do conceito de gênero exige um conjunto interdisciplinar e pós-disciplinar de discursos, com vistas a resistir à domesticação acadêmica dos estudos sobre gênero ou dos estudos sobre as mulheres, e a radicalizar a noção da crítica feminista (p. 13).

Decorre dessa leitura a convicção de que não se pode pensar o conceito de gênero feminino como um problema circunscrito à noção de "mulheres", mas que envolve várias formas de opressão interligadas. É o que defende Kimberle Crenshaw, responsável pelo desenvolvimento teórico do conceito da interseção das desigualdades de raça, de gênero e de classe social, no final da década de oitenta do século 20, ao criar o termo "feminismo interseccional". Em documento no qual apresenta com clareza essa noção, bem como algumas recomendações, Crenshaw (2002, p. 171) adverte:

A ampliação dos direitos humanos das mulheres nunca esteve tão evidente como nas determinações referentes à incorporação da perspectiva de gênero (gender mainstreaming) das conferências mundiais de Viena e de Beijing. De fato, ao mesmo tempo que a diferença deixou de ser uma justificativa para a exclusão do gênero dos principais discursos de direitos humanos, ela, em si mesma, passou a servir de apoio à própria lógica de incorporação de uma perspectiva de gênero. Tal incorporação baseia-se na visão de que, sendo o gênero importante, seus efeitos diferenciais devem necessariamente ser analisados no contexto de todas as atividades relativas aos direitos humanos. Assim, enquanto no passado a diferença entre mulheres e homens serviu como justificativa para marginalizar os direitos das mulheres e, de forma mais geral, para justificar a desigualdade de gênero, atualmente a diferença das mulheres indica a responsabilidade que qualquer instituição de direitos humanos tem de incorporar uma análise de gênero em suas práticas. 
É preciso ter clareza de que a estrutura de gênero é ideológica e que a ideologia de gêneros é hegemônica, porque frequentemente não se apresenta como dominação, mas como consensual e aceitável numa comunidade, senão naturalizada. Gramsci (1987), ao definir ideologia como concepção de mundo, questionava se haveria ideologias mais ou menos favoráveis a determinados grupos ou pessoas, individualmente. Essa preocupação encerra-se - particularmente no que se refere à temática deste nosso estudo - no fato de muitas mulheres adotarem a ideologia religiosa cristã, por exemplo, que, por ser essencialmente patriarcal', é-lhes totalmente desfavorável, tanto pelo fato de que lhes nega os direitos sobre o seu próprio corpo, quanto por lhes assujeitar aos homens.

A análise crítica feminista de discursos como práxis política, conforme defende Lazar (2005), é capaz de dar conta dessa problemática, ao estabelecer como preocupação central criticar discursos que sustentam uma ordem social patriarcal, ou seja, relações de poder que sistematicamente privilegiam homens como grupo social e que prejudicam, excluem e desempoderam mulheres como grupo social. A autora adverte que essas práticas não são neutras, mas dessa forma engendradas. A natureza de gênero dessas práticas sociais pode ser descrita, segundo a autora, em dois níveis: a) "gênero" funciona como uma categoria interpretativa que permite aos participantes de uma comunidade tomar sentido e estruturar suas práticas sociais particulares e b) "gênero" é uma relação social que penetra e parcialmente constitui todas as outras relações e atividades sociais (LAZAR, 2005).

Assim é que os discursos de gênero instituem as relações sociais e as diferenças entre os sexos, o que é feito por meio de construções simbólicas que determinam e mantêm o status quo, atribuindo papéis a um ou outro gênero, ou seja, envolve o conjunto de expectativas sociais e padrões de comportamento. Martins Ferreira (2009) chama a atenção para o fato de que essas diferenças são reveladas nas práticas discursivas, em que muitas mulheres, como já foi anteriormente ressaltado, adotam a ideologia patriarcal e sexista. Em suas palavras: "No universo da dicotomia sexista patriarcal, a natureza masculina espelharia objetividade,

\footnotetext{
${ }^{7}$ Não é por acaso que Deus é retratado como um homem velhinho de barba (o homem sábio) e que no dicionário os nomes que admitem pares feminino e masculino têm sua entrada no masculino: "moço" e não "moça".
} 
racionalidade e segurança, e a feminina, características de dispersão, emoção e de pouca segurança” (p. 116).

\subsection{Estudos críticos de discursos}

Os estudos críticos de discursos almejam investigar criticamente como a desigualdade social é expressa, sinalizada, constituída, legitimada, e, também desconstruída, por meio do uso da linguagem (ou no discurso). A desconstrução desses discursos é tarefa da Análise Crítica de Discursos (doravante, ACD), cujo interesse particular centra-se na relação entre linguagem, ideologia e poder. A ACD pode, então, ser definida como um campo dentro dos estudos críticos da linguagem fundamentalmente interessado em analisar relações estruturais, transparentes ou veladas, de discriminação, poder e controle manifestas na linguagem. Assim é que a Teoria Social do Discurso baseia-se em uma percepção da linguagem como parte irredutível da vida social dialeticamente interconectada a outros elementos sociais (RAMALHO; RESENDE, 2006), ou seja, o discurso é moldado pela estrutura social, mas também é constitutivo da estrutura social.

Para garantir a dominação, o poder e a manutenção das desigualdades, Teun van Dijk (2008) assevera que grupos poderosos controlam o discurso público pela concessão ou não do acesso a esses discursos - acesso definido pelo contexto (cenário, ações, participantes, representações mentais), pelas estruturas do texto (gêneros textuais, atos de fala) e pelos temas (macroestruturas semânticas). Em consequência, esse discurso controla as mentes e as ações dos indivíduos, que tendem a aceitar crenças, desde que produzidas por aqueles considerados fontes autorizadas, confiáveis ou críveis, ou pelo desconhecimento desses indivíduos sobre o discurso ou informação a que são expostos. É dessa forma que são formados e/ou reformulados os modelos mentais e as representações sociais, conforme postulam Chouliaraki e Fairclough (1999):

Discurso, portanto, apresenta-se de duas maneiras nas práticas: práticas são parcialmente discursivas (falar, escrever, etc, é apenas um modo de ação), mas elas são também discursivamente representadas. Na medida em que tais representações ajudam a sustentar relações de 
dominação nessas práticas, elas são ideológicas (p. 37, tradução nossa.). ${ }^{8}$

É com base nessas considerações que os estudos do discurso são críticos e, metodologicamente, segundo van Dijk (2008), devem observar alguns dos seguintes critérios:

a) estudo das relações de dominação pelo grupo dominado e do seu interesse;

b) uso das experiências dos grupos dominados para avaliar o discurso dominante;

c) denúncia da ilegitimidade das ações discursivas do grupo dominante;

d) formulação de alternativas viáveis aos discursos dominantes.

Na perspectiva de gênero, há, segundo Lazar (2005), várias razões para se fazer uma análise crítica feminista ${ }^{9}$ de discursos, entre as quais se destacam:

a) ACD oferece uma teorização sofisticada das relações entre práticas sociais e estruturas discursivas, além de uma gama de ferramentas e estratégias para uma análise acurada dos usos reais e contextualizados da linguagem.

b) Análise crítica de discursos na perspectiva de gênero preocupa-se em desmistificar as inter-relações de gênero, poder e ideologia nos discursos, numa visão multimodal.

Relações de poder e dominação, entretanto, podem ser discursivamente confrontadas, num embate dinâmico para assegurar ou desafiar os interesses em jogo. Exatamente esta é a tarefa da ACD

\footnotetext{
${ }^{8}$ No original: Discourse therefore figures in two ways within practices: practices are partly discursive (talking, writing, etc. is one way of acting), but they are also discursively represented. In so far as such representations help sustain relations of domination within the practice, they are ideological.

${ }^{9}$ Vale a ressalva de que o termo feminino pode ter significados ideológicos diversos, tais como a noção de gênero biológico (questão de diferenças de genitália e não de escolha práxis sexual), social e cultural (no que tange a percepção de estilização de corpo [BUTLER, 2016], preconceitos e exclusão) e político (o movimento feminista que reivindica direitos iguais, iniciado na década de 60) (MARTINS FERREIRA, 2009).
} 
na perspectiva de gênero: examinar como o poder e a dominação são discursivamente produzidos e/ou confrontados de formas variadas pelas representações textuais de práticas sociais de gênero e por meio de estratégias interacionais de conversação (LAZAR, 2005).

Para que sejam, pois, observados alguns critérios para uma metodologia da análise de discursos de gêneros, dois conceitos são indispensáveis para a ACD: o conceito de poder e o conceito de ideologia, que abordaremos neste estudo por responderem com mais propriedade as questões eleitas para a análise de nosso corpus.

\subsection{Ideologia e poder}

O conceito de ideologia já se consagrou nos estudos do discurso como um conceito muito complexo. São tantos estudiosos e tantas formas de abordagem que já se cogitou não mais considerá-lo como importante, por exemplo, para se analisar determinados discursos. Como não podemos concordar com essa última tendência, digamos assim, buscamos traçar um breve panorama do que esse conceito representa nesta nossa investigação.

Thompson (1990) nos lembra que o conceito de ideologia surgiu no século XVIII na França e tem sido utilizado numa gama de funções e significados ao longo desses mais de dois séculos. Para ele, ideologia refere-se a processos e formas sociais no interior dos quais e por meio dos quais circulam formas simbólicas no mundo social. Dessa forma, o estudo da ideologia tenta explicar como o significado é construído e transmitido por meio de diferentes formas simbólicas.

Ao contrário da visão determinista do poder da ideologia sobre o sujeito na primeira fase da Análise do Discurso, para os analistas críticos do discurso, como Fairclough (2001), Wodak (2005), van Dijk (2008), Chouliaraki e Fairclough (1999), a ideologia é vista como um importante aspecto da criação e manutenção de relações desiguais de poder, e, nesse sentido, “[...] ideologias são significações/construções da realidade [...] que são construídas em várias dimensões das formas/sentidos das práticas discursivas e que contribuem para a produção, a reprodução ou a transformação das relações de dominação" (FAIRCLOUGH, 2001, p. 17). Embutidas nas práticas discursivas - continua o autor -, as ideologias são muito eficazes quando se tornam naturalizadas e atingem o status de 'senso comum'. Nesse caso, alguns aspectos ou níveis do texto e do discurso que podem ser investidos ideologicamente são especialmente 
os semânticos (pressuposições, metáforas e coerência). Ou seja, é exatamente nos discursos que a eficácia da ideologia se consolida, pois esta deriva do fato de que se confere às palavras não só um sentido, mas também um poder: poder de persuasão, de convocatória, de consagração, de estigmatização (HAIDAR, 2000). Uma vez que o poder depende da conquista do consenso e não apenas de recursos para o uso da força, a ideologia tem importância na sustentação de relações de poder.

Ricoeur (1981) tem posição um pouco diferente: a ideologia não pode se confinar a uma definição que toma por base exclusivamente a de dominação de classe. Para sustentar isso, analisa o conceito de ideologia, considerando algumas funções: mediar a integração social, de forma a tornar um determinado grupo coeso; dominar - e para isso provê a legitimidade necessária ao exercício da autoridade sendo um sistema justificador da dominação; deformar, que é função importante em cuja instância encontra-se a própria noção marxista de ideologia e na qual se fundem as duas outras instâncias analisadas antes. Ricouer salienta que, para garantir a coesão de um grupo e dominá-lo, alguns mecanismos são necessários, tais como: a) perpetuar um ato fundador inicial, o qual instaura uma memória que é transmitida adiante e dá identidade ao grupo; b) estimular a praxis social por meio de dinamismo e motivação; c) reduzir o grau de complexidade da análise da realidade para o grupo, por meio de simplificação e esquematização, pelo uso de elementos retóricos, como máximas, slogans, entre outros; d) agir por meio de nós, pela operabilidade e pela atematicidade, ou seja, a ideologia serve de ponto de partida para nossos pensamentos, mesmo que pensemos que nossos pensamentos são o ponto de partida para o alcance daquela; e) demonstrar intolerância pelo novo, justificando esse como algo perigoso e capaz de desestabilizar e separar o grupo.

Fairclough, baseando-se no conceito de hegemonia elaborado por Gramsci (ver GRAMSCI, 1978; 1987), preocupa-se em acentuar a noção de discurso como "modo de prática política e ideológica" (FAIRCLOUGH, 2001, p. 94) e ressalta:

O discurso como prática política estabelece, mantém e transforma as relações de poder e as entidades coletivas $[\ldots]$ entre as quais existem relações de poder. $\mathrm{O}$ discurso como prática ideológica constitui, naturaliza, mantém e transforma os significados do mundo de posições diversas nas relações de poder. 
Considerando-se o discurso nessa perspectiva, um fenômeno que é objeto de análise de estudiosos é a naturalização do discurso, conforme postula Thompson (1990), que é uma estratégia para legitimar, dissimular, unificar, fragmentar e reificar relações de dominação, o que é bastante perigoso, uma vez que pode levar indivíduos a reproduzir ideologias que os prejudicam a si ou a outros. Por exemplo, é "por meio do discurso [...] que muitas mulheres adotam a ideologia patriarcal e sexista que lhes é desfavorável e que muitos trabalhadores adotam a ideologia burguesa que também vai contra seus interesses e aspirações" (OLIVEIRA, 2013, p. 41), o que os faz se submeterem a relações desiguais de opressão e poder.

Maffesoli (2011) elabora uma dicotomia interessante entre "poder" (pouvoir) e "potência" (puissance). Segundo o que ele denomina de dialética fundadora, ou, melhor dizendo, dialogia, considerando que um termo remete ao outro, potência (instituinte) "é exatamente o que constitui o elemento básico da vida em comum" (p. 17). É o que se pode considerar de "impulso vital". O poder (instituído) "é, de alguma maneira, a institucionalização [...], a legitimação, a racionalização dessa força primitiva, desse impulso vital' (p. 18). Retomando essa questão na obra O Tempo das Tribos (2006), Maffesoli apresenta uma segunda lei: "O poder pode e deve se ocupar da gestão da vida; a potência é responsável pela sobrevivência" (p. 115).

Mas é preciso ter claro, como alerta Foucault (1979, p. 86), que o poder "é tolerável somente na condição de que mascare uma grande parte de si mesmo. Seu sucesso é proporcional à sua habilidade para esconder seus próprios mecanismos". Em outras palavras, muitas vezes as formas como os discursos são apresentados materializam e naturalizam formas de controle do poder social - controle de um grupo sobre outros grupos e seus membros - pela força potencial, locucionária, ilocucionária e perlocucionária do texto. A conquista do consentimento é, portanto, um trabalho discursivo, alicerçado em aparelhos ideológicos da sociedade, principalmente os órgãos da mídia (impressa ou eletrônica) e o sistema escolar. 


\section{Procedimentos metodológicos}

\subsection{O campo do estudo}

Tendo em vista que o nosso objetivo é também analisar como os discursos discriminatórios se materializam e se difundem em comunidades acadêmicas, ou seja, em contextos de realização de linguagem cujos sujeitos estariam teoricamente mais atentos às diferentes posições ideológicas e aos modos de como elas se manifestam, efetuamos este estudo em duas grandes instituições de ensino superior - uma universidade federal e uma universidade particular, localizada em um dos centros urbanos mais populosos do nordeste do Brasil.

Não foi nossa intenção comparar práticas de linguagem em outras regiões do Brasil, sendo, portanto, a escolha desse campo uma forma de podermos ter acesso a maior número de sujeitos nessas instituições, considerando-se o tempo do estudo, que é de doze meses, e a localização do Programa onde pretendíamos desenvolver a pesquisa. Entretanto, fizemos levantamentos de dados - que serão apresentados ao longo da análise - sobre mulheres em funções públicas, apresentados por institutos na França, a exemplo da Sorbonne, em Paris, onde estivemos para aprofundar os estudos durante o período do estágio.

\subsection{As entrevistadas}

As práticas discursivas que compõem o corpus de nossa análise vieram, majoritariamente, de mulheres que ocupam posições de liderança nas instituições pesquisadas. São coordenadoras de cursos (graduação e pós-graduação), chefes ou diretoras de departamento/centros acadêmicos, diretoras ou gerentes de setores administrativos, pró-reitoras, reitora e diretoras de instituição. Cada uma dessas posições foi representada por pelo menos uma mulher, mas houve casos em que tivemos mais de duas mulheres representando a mesma função nas diferentes instituições pesquisadas, a exemplo de coordenadoras de cursos. No caso de reitora, dado que é o maior posto a se ocupar em instituições acadêmicas, e, de forma geral, de número muito reduzido em todo o país, comparando-se com o de homens que exercem esses cargos, só uma foi entrevistada. ${ }^{10}$

\footnotetext{
${ }^{10}$ A Associação Nacional dos Dirigentes das Instituições Federais de Ensino Superior - Andifes, criada em 23 de maio de 1989, é a representante oficial das universidades federais no Brasil. Entre as 67 instituições que fazem parte dessa Associação, apenas
} 
Assim, nossa amostra compreendeu o número de 12 mulheres, que pode parecer pequeno, considerando o universo de mulheres trabalhadoras no mundo todo, mas é representativo, em grande escala, do número de mulheres que atuam em altos postos de decisão, seja no setor público, seja no privado.

Um estudo feito pela ONU, Mulheres do Mundo 2010: Tendências e Estatísticas, ${ }^{11}$ apresenta estatísticas e análises sobre a situação das mulheres e dos homens no mundo, destacando a situação atual e as mudanças ao longo do tempo. As análises são baseadas principalmente em estatísticas de agências nacionais e internacionais. Um dos temas analisados no relatório, que abrange 196 países ou áreas com uma população mínima de 100.000 habitantes, diz respeito ao exercício de poder e tomada de decisões das mulheres. Entre as principais constatações apresentadas nesse estudo, destacam-se as seguintes ${ }^{12}$ :

- Tornar-se Chefe de Estado ou Chefe de Governo permanece ilusória para mulheres. Apenas 14 mulheres no mundo atualmente detêm ou uma ou outra posição.

- Em apenas 23 países, as mulheres compreendem um número expressivo - mais de 30 por cento - no seu parlamento nacional.

- Em todo o mundo, em média, apenas uma em cada seis ministros é mulher.

19 são dirigidas por mulheres, o que representa um percentual de $28 \%$. (http://www. andifes.org.br/institucional/a-andifes/)

11 The World's Women 2010. United Nations. New York, 2010. Department of Economic and Social Affairs.

12 - Becoming the Head of State or Head of Government remains elusive for women, with only 14 women in the world currently holding either position.

- In just 23 countries do women comprise a critical mass - over 30 per cent - in the lower or single house of their national parliament.

- Worldwide on average only one in six cabinet ministers is a woman.

- Women are highly underrepresented in decision-making positions at local government levels.

- In the private sector, women continue to be severely underrepresented in the top decision making positions.

- Only 13 of the 500 largest corporations in the world have a female Chief Executive Officer.

Este estudo não foi traduzido para a língua portuguesa. 
- As mulheres são extremamente sub-representadas em posições de tomada de decisão nos governos locais.

- No setor privado, as mulheres continuam a ser fortemente subrepresentadas no topo das posições de tomada de decisão.

- Apenas 13 das 500 maiores empresas do mundo têm uma mulher como Chefe do Executivo. (Tradução nossa)

$\mathrm{Na}$ análise do corpus de nosso estudo, esses e outros aspectos foram considerados, tais como as diferenças entre mulheres, expressas nos modos de ação discursiva, que compreendem variáveis como pertencimento a diferentes classes socioeconômicas, níveis de formação educacional, base cultural e idade.

Uma consideração que se faz necessária para a apresentação das entrevistadas é que todas elas se mostraram disponíveis e interessadas em fazer parte deste estudo. $\mathrm{O}$ fato de que todas pertencem ao universo acadêmico, em que uma das principais atividades, ao lado do ensino e da extensão, é a pesquisa, torna-as conscientes de que as suas respostas contribuirão para esclarecer algumas hipóteses que são aqui levantadas. Foi feita uma advertência formal, na ocasião da entrega dos questionários e da realização da pesquisa, relacionada ao sigilo das suas identidades, mas, independentemente disso, elas se mostraram confortáveis e cooperativas com os instrumentos de pesquisa.

O tempo de permanência no cargo, na ocasião das entrevistas, variou entre 6 meses e 5 anos. Neste último caso, apenas uma delas permaneceu mais tempo. A maioria encontrava-se no cargo por mais de 3 anos. Das 12 entrevistadas, 7 pertenciam à instituição pública federal, e 5 pertenciam à instituição privada, ressaltando-se que ambas são instituições de grande porte. Como bem sabemos, nas instituições públicas, esses cargos têm, regimentalmente, um tempo de gestão que varia entre dois e quatro anos, podendo haver a recondução por igual período. Apenas 2 delas foram reconduzidas: uma por eleição e outra por indicação. As formas de ocupação do cargo foram equitativamente distribuídas entre as entrevistadas: 4 foram eleitas, 4 foram indicadas e as outras 4 foram convidadas.

Um dado que muito nos interessava anotar referia-se à faixa etária das entrevistadas: $75 \%$ das mulheres tinham mais de 36 anos. Sem que precisássemos recorrer a estatísticas feitas por institutos de pesquisa, é de conhecimento geral que os cargos mencionados geralmente são 
preenchidos por pessoas não tão jovens, pelo fato de que, mesmo em instituições com eleições, em que as candidaturas são livres, o acesso a esses postos requer experiência e formação, que não são tão facilmente encontradas em profissionais muito jovens.

Considerando a hipótese que construímos para iniciar esta pesquisa que visa investigar o fato de muitas mulheres incorporarem e reproduzirem os discursos discriminatórios para explicar suas condições de vida e trabalho, procuramos identificar em que medida mulheres que atuam em espaços de produção e divulgação de conhecimento, como é o caso de instituições de ensino superior, podem reproduzir as ideologias embutidas nas práticas discursivas ou a elas se contraporem. Essa assunção pode estar diretamente ligada à formação acadêmica de nossas entrevistadas, que pode torná-las, pelo menos hipoteticamente, mais atentas às diferentes posições ideológicas e aos modos de como elas se manifestam, e, por conseguinte, mais ou menos, a elas refratárias. Apresentada, na tabela seguinte, a disposição das entrevistadas nos seus diferentes níveis de estudo, podemos constatar que a maior parte delas tem curso de pós-graduação stricto sensu, como mestrado (3) doutorado (6) e pós-doutorado (1).

TABELA 1 - Formação Acadêmica

\begin{tabular}{c|c}
\hline Especialização: & 2 \\
\hline Mestrado: & 3 \\
\hline Doutorado: & 6 \\
\hline Pós-doutorado: & 1 \\
\hline
\end{tabular}

Fonte: Elaborada pelas autoras.

\subsection{A análise macro e microestrutural do corpus}

Van Dijk (2008) sugere alguns procedimentos metodológicos para os estudos críticos do discurso que aqui tentaremos levar a cabo. Um deles, mais global, é a análise das macroestruturas semânticas, que são os tópicos ou temas dos textos, geralmente intencionais e controlados pelo enunciador, expressos em títulos, resumos, sumários. Outro, mais local, é a análise das microestruturas semânticas, que dizem respeito às 
escolhas lexicais e sintáticas, às relações proposicionais e aos recursos extralinguísticos feitos pelo produtor do texto.

Considerando que a ideologia se opera e se consolida por meio de estratégicas de construção simbólica (no caso, pelo discurso), que ajudam a manter estáveis relações de dominação e poder, pretendemos empreender nossa análise com a convicção de que o "que qualifica o analista do discurso é considerar que o discurso não é um simples suporte, mas que desempenha um papel constitutivo nos processos ideológicos" (MAINGUENEAU, 2010, p.75). Para esse empreendimento, tomamos por base um interessante modelo de análise de Thompson (1990) para identificar como essas estratégias estão presentes nos discursos de forma a legitimar, dissimular, unificar, fragmentar e reificar relações de dominação. Desses cinco modos de operação de ideologia, destacamos os que serão utilizados e suas respectivas estratégias na análise de nosso corpus:

QUADRO 1 - Modelo de Thompson (1990)

\begin{tabular}{|c|c|}
\hline $\begin{array}{c}\text { Modos Gerais } \\
\text { de Operação da Ideologia }\end{array}$ & $\begin{array}{l}\text { Estratégias Típicas } \\
\text { de Construção Simbólica }\end{array}$ \\
\hline \multirow[b]{2}{*}{$\begin{array}{l}\text { LEGITIMAÇÃO - Relações de } \\
\text { dominação são representadas } \\
\text { como legítimas }\end{array}$} & $\begin{array}{l}\text { FALÁCIAS ARGUMENTATIVAS (Exemplo: } \\
\text { apelos à legalidade, a bases jurídicas, científicas) }\end{array}$ \\
\hline & $\begin{array}{l}\text { NARRATIVIZAÇÃO (exigências de } \\
\text { legitimação inseridas em histórias do passado } \\
\text { que legitimam o presente) } \\
\text { Exemplo: tradições, costumes, pessoas }\end{array}$ \\
\hline $\begin{array}{l}\text { REIFICAÇÃO - Retratação de } \\
\text { uma situação transitória como } \\
\text { permanente e natural }\end{array}$ & $\begin{array}{l}\text { NATURALIZAÇÃO (criação social e histórica } \\
\text { tratada como acontecimento natural) }\end{array}$ \\
\hline \multirow{3}{*}{$\begin{array}{l}\text { DISSIMULAÇÃO - Relações } \\
\text { de dominação são ocultadas, } \\
\text { negadas ou obscurecidas }\end{array}$} & $\begin{array}{l}\text { DESLOCAMENTO (deslocamento contextual } \\
\text { de termos e expressões) }\end{array}$ \\
\hline & $\begin{array}{l}\text { EUFEMIZAÇÃO (valoração positiva de } \\
\text { instituições, ações ou relações) }\end{array}$ \\
\hline & TROPO (sinédoque, metonímia, metáfora) \\
\hline
\end{tabular}

Fonte: Adaptado pelas autoras. 
Essas estratégias se realizam nos discursos por meio de diferentes recursos da linguagem (verbais ou não verbais), tais como a presença de sons e mudanças de entonação; escolhas sintáticas de construção do enunciado (uso de orações na voz passiva ou ativa, por exemplo); escolhas lexicais (seleções de palavras mais ou menos negativas, incluindo tempos e modos verbais); dispositivos retóricos (uso de metáforas e figuras de linguagem), entre tantos outros, que respondem, direta ou indiretamente, pela construção dos discursos (discriminatórios ou não) que circulam nas sociedades.

Avaliações, por exemplo, que representam uma categoria identificacional moldada por estilos, são apreciações ou perspectivas do locutor, mais ou menos explícitas, sobre aspectos do mundo. Os modos de operação da ideologia nessa categoria se dão principalmente pela dissimulação, em que relações de dominação são obscurecidas por eufemismos, ou seja, na valoração positiva de ações e relações nada desejáveis, e pela reificação, que torna permanente e natural a representação de uma situação transitória, por meio da naturalização.

Desse modelo, são aqui destacadas algumas dessas estratégias identificadas nos discursos dessas mulheres, ao mesmo tempo que serão observados os recursos de linguagem utilizados para a construção desses enunciados que apresentam marcas de legitimação, dissimulação e reificação, isto é, os modos de operação da ideologia que sustentam relações de poder e dominação por meio de discursos discriminatórios.

Todos esses elementos serão acionados à medida que estiverem sendo apresentados os recortes das falas das entrevistadas ou das respostas às questões formuladas no questionário, que foram divididas em duas partes.

\subsection{Os instrumentos de pesquisa}

Foi aplicado um questionário, enviado por e-mail às mulheres desta pesquisa, e entrevistas foram realizadas, a fim de compreendermos, com base nas análises de seus discursos, as relações de gênero e o papel das mulheres nos espaços que ocupam nas instituições, ao assumirem posições de liderança. Esse questionário foi elaborado levando-se em conta os modelos que dão sustentação à $\mathrm{ACD}$, que orienta nossa análise dos dados e resultados desta pesquisa. 
Dividido em duas partes, o questionário visa avaliar a forma como essas mulheres veem sua posição no mundo do trabalho da academia e como avaliam a forma como são vistas pelos demais integrantes desse mundo foram fundamentais para tecermos nossa análise.

1. Na primeira parte, foram feitas afirmações extraídas de discursos comumente repetidos na mídia (eletrônica ou impressa), na literatura (de ficção ou não-ficção), em materiais didáticos, enfim, em várias situações de usos de linguagem que legitimam, reificam ou dissimulam relações de dominação e discriminação. Para saber o grau de concordância ou discordância relativas a essas afirmações, foi utilizada a escala de Likert, que utiliza 5 pontos assim discriminados: concordo plenamente; concordo parcialmente; não concordo nem discordo; discordo parcialmente; discordo totalmente.

2. Na segunda parte, foram feitas perguntas que buscavam entender, entre tantas coisas, como elas se veem nas suas relações de trabalho e interpessoais.

\section{Análise dos dados}

\section{$1^{\text {a }}$ parte - Como as entrevistadas avaliam o que se diz sobre elas}

$\mathrm{Na}$ escala, encontram-se os percentuais das avaliações feitas pelas entrevistadas a respeito das afirmações, que serão comentadas nesta parte da análise. 
TABELA 2 - Percentuais das avaliações feitas pelas entrevistadas

\begin{tabular}{c|c|c|c|c|c}
\hline \multicolumn{1}{c|}{ Afirmações } & $\begin{array}{c}\text { Concordo } \\
\text { plenamente }\end{array}$ & $\begin{array}{c}\text { Concordo } \\
\text { parcialmente }\end{array}$ & $\begin{array}{c}\text { Não concordo } \\
\text { nem discordo }\end{array}$ & $\begin{array}{c}\text { Discordo } \\
\text { parcialmente }\end{array}$ & $\begin{array}{c}\text { Discordo } \\
\text { totalmente }\end{array}$ \\
\hline $\begin{array}{c}\text { a) Não faz diferença ser uma } \\
\text { empresa/instituição dirigida } \\
\text { por homem ou mulher }\end{array}$ & $5(41 \%)$ & $2(17 \%)$ & $3(25 \%)$ & $2(17 \%)$ \\
\hline $\begin{array}{c}\text { b) A mulher é mais emocional } \\
\text { e o homem mais racional } \\
\text { nas tomadas de decisão. }\end{array}$ & $2(17 \%)$ & $4(33 \%)$ & $3(25 \%)$ & $3(25 \%)$ \\
\hline $\begin{array}{c}\text { c) As mulheres são melhores } \\
\text { que os homens para efetuar } \\
\text { tarefas manuais, repetitivas, } \\
\text { que exigem atenção, } \\
\text { paciência e coordenação } \\
\text { motora. }\end{array}$ & $1(8 \%)$ & $1(8 \%)$ & $2(17 \%)$ & $4(33 \%)$ & $4(33 \%)$ \\
\hline $\begin{array}{c}\text { d) Mulheres e homens têm } \\
\text { as mesmas oportunidades } \\
\text { para assumirem cargos de } \\
\text { poder, desde que estejam } \\
\text { preparados para isso. }\end{array}$ & $3(25 \%)$ & $1(8 \%)$ & $1(8 \%)$ & $4(33 \%)$ & $3(25 \%)$ \\
\hline $\begin{array}{l}\text { e) A liderança é um aspecto } \\
\text { naturalmente encontrado no } \\
\text { homem. }\end{array}$ & & & $2(17 \%)$ & $10(83 \%)$ \\
\hline
\end{tabular}

Fonte: Elaborada pelas autoras.

\section{a) Não faz diferença ser uma empresa/instituição dirigida por homem ou mulher.}

Entre as que discordaram totalmente, destacamos o seguinte comentário:

O reconhecimento ou o fracasso representam a desqualificação da mulher. No primeiro, ela é associada ao homem, e, no segundo, ela não deu certo porque é mulher. As mulheres têm mais capacidade de trabalhar as diferenças. O homem é cartesiano, maniqueísta. Para ele 
uma coisa ou é boa ou é ruim. Isso é uma questão social, e não biológica.. $(11 A)^{13}$

Apesar de demonstrar consciência das formas de representação de "sucesso" e "fracasso" atribuídas às mulheres na condução de cargos de poder, na primeira parte de seu depoimento, a entrevistada reproduz o discurso ideologicamente naturalizado ao utilizar os termos de avaliação como "cartesiano" e "maniqueísta" para os homens, na comparação com as mulheres. Observe-se que o comentário seguinte de uma das entrevistadas que concordava parcialmente com a afirmação não difere muito, em conteúdo avaliativo:

Acredito que as mulheres têm um olhar mais humanizado para o outro e considero que nesse aspecto supera os homens quando administram. (3A)

Butler (2016) adverte sobre o risco dessas afirmações totalizantes da crítica feminista e ressalta que o "esforço de identificar o inimigo como singular em sua forma é um discurso invertido que mimetiza acriticamente a estratégia do opressor, em vez de oferecer um conjunto diferente de termos" (p. 37).

Essa dicotomia homem $\mathrm{x}$ mulher tem sido frequente nos discursos sobre relações de poder, o que reforça a necessidade de se pensar de forma conjunta as dominações, de modo a não contribuir para sua reprodução.

\section{b) A mulher é mais emocional e o homem mais racional nas tomadas de decisão.}

Mesmo escolhendo a alternativa "não concordo nem discordo", que representou a maioria nessa afirmação, uma das entrevistadas, ao se expressar que considerava "a mulher mais emocional, e isso pode influenciar em algumas atitudes no trabalho (12B)", confirma a hipótese de que relações de dominação, em que se consideram alguns comportamentos como inatos, são representadas como naturais, como um modo de operação de ideologias.

É evidente que a hegemonia ideológica 'total', tal como denunciada em alguns estudos, é uma visão de mundo redutora e simplista.

${ }^{13}$ LEGENDA: 1 a 12 = entrevistadas; A = instituição pública; $\mathrm{B}$ = instituição privada. 
Fairclough (2001) argumenta que essa dominação hegemônica não seria tão uniforme como se crê, pois funcionaria como uma "construção de alianças e integração" um "equilíbrio instável” [...], "muito mais do que simplesmente a dominação de classes subalternas, mediante concessões ou meios ideológicos para ganhar seu consentimento" (FAIRCLOUGH, 2001, p.122). É preciso considerar, entretanto, que, quando a ideologia presente na prática discursiva já faz parte do senso comum, esse equilíbrio não é percebido, e o sujeito considerar como seu aquilo que constrói discursivamente sem perceber que há uma luta, um jogo de poder e que esse embate se dá também por meio das práticas discursivas, isto é, da produção, reprodução e transformação dos discursos estabelecidos em outros discursos, também ideologicamente forjados.

\section{c) As mulheres são melhores que os homens para efetuar tarefas manuais, repetitivas, que exigem atenção, paciência e coordenação motora.}

A grande maioria das mulheres entrevistadas discordou, parcialmente ou totalmente (34\% e $33 \%$, respectivamente), dessa afirmação, argumentando, em seus comentários, que a força cultural sustenta essa visão, como explicitamente defende a entrevistada $2 \mathrm{~A}$ e implicitamente reforçam 11A e12B.

Essa é uma visão cultural, mas não é verdadeira. (2A)

As pessoas não são feitas para isso ou aquilo. (11A)

Independe do gênero. Depende da habilidade individual. (12B)

Dizem as pesquisas que sim, pela paciência e capacidade de concentração, e se percebe que elas realmente rendem mais nessas tarefas. (3A)

$\mathrm{O}$ discurso da entrevistada $3 \mathrm{~A}$ reforça o clichê, conhecido em todas as partes do mundo, referido por Boyer (2016): "Todos os homens seriam líderes natos, com talentos genéticos que os predispõem a se 
tornarem chefes, sem esforço, enquanto as mulheres, doces e submissas, seriam secretárias perfeitas, com o seu senso de organização doméstica."14

Clichês, assim como as falácias, funcionam com muita eficiência para legitimar relações de dominação (THOMPSON, 1990). Afirmações muitas vezes e largamente repetidas, ainda que não sejam verdadeiras, passam a se tornar incontestáveis, sobretudo quando vêm respaldadas, como o faz a entrevistada, por "pesquisas", sejam elas de qualquer natureza - ou de natureza nenhuma.

\section{d) Mulheres e homens têm as mesmas oportunidades para assumirem cargos de poder, desde que estejam preparados para isso.}

Surpreende o percentual de concordância com essa frase (41\%), que varia na escala entre concordar plenamente até nem concordar nem discordar, uma vez que foram reiteradas as afirmações, em outras falas, de que as mulheres não têm as mesmas oportunidades que os homens. Essa contradição talvez possa ser explicada por ser a ideologia de gêneros hegemônica, frequentemente, não se apresentando como dominação, mas como consensual e aceitável numa comunidade (LAZAR, 2005).

Entretanto, entre as que discordaram (totalmente ou parcialmente), observamos posições bastante céticas em relação a uma suposta "igualdade de oportunidades" para homens e mulheres, como podemos ver nas falas seguintes.

Têm as mesmas possibilidades, mas não as mesmas oportunidades. (2A)

Não acredito na igualdade total de oportunidades. [...] É fácil mudar uma lei, mas difícil e demorado mudar uma cultura machista, de mais de cinco séculos de predominância masculina no Brasil. Mulheres mais preparadas, mais escolarizadas, sendo preteridas por homens menos

\footnotetext{
${ }^{14}$ Les femmes et la haute fonction publique : interview de Bénédicte Boyer, journaliste et auteure du livre éponyme - 25/04/2013. Disponível em: <http://www.fonctionpublique.gouv.fr/fonction-publique-1135>. Acesso em: fev. 2016. Tradução nossa. No original: « tous les hommes seraient des leaders-nés possédant des talents génétiques les prédisposant à devenir chef sans effort, tandis que les femmes, douces et soumises, feraient des secrétaires parfaites avec leur sens de l'organisation domestique ».
} 
preparados e menos escolarizados, simplesmente por serem homens. (3A)

Ela pode ser a melhor, mas a tendência é escolher o homem, pois o discurso é que as mulheres têm mais problemas biológicos que a fazem se afastar mais do trabalho, como TPM, gravidez. (11A - grifos nossos).

Observe-se que uma das estratégias típicas de construção simbólica para sustentar relações de dominação como legítimas é apelar para a ciência ou dados estatísticos. A entrevistada $11 \mathrm{~A}$ ressalta a tendência desse discurso (destacada na sua fala) e suas implicações na desigualdade de oportunidades.

\section{e) A liderança é um aspecto naturalmente encontrado no homem.}

Contrapondo-se ao apelo biológico do sexo, praticamente todas as entrevistadas discordaram, totalmente $(83 \%)$ ou parcialmente $(17 \%)$, dessa afirmação, revelando a compreensão de que as distinções entre o feminino e o masculino não são fatos naturais, mas, ao contrário, são forjadas pelos indivíduos em sociedade e perpassadas pela cultura, como bem defende Butler (2016).

Liderança independe de gênero, mas manifestá-la depende das circunstâncias, do contexto, da necessidade e nossa sociedade ainda apresenta restrições em relação às lideranças femininas devido à cultura machista que ainda resiste às mudanças. (3A)

Muitas vezes o homem se apresenta como líder (pelo reconhecimento), mas a mulher é que está gerindo e conduzindo por trás. Há mulheres que são melhores que os homens na liderança. Liderança é carisma, por história de vida. (11A)

Existem pessoas com habilidades para liderança. Não precisam ser homens. (12B)

O discurso ideológico que afirma que algumas características não são próprias dos seres humanos, mas sim de cada um dos sexos distintamente revela a eficácia do poder moderno (e sua hegemonia), e 
este é principalmente cognitivo, baseado numa internalização de regras de gênero e operado rotineiramente nos textos e nas conversações do dia-a-dia (LAZAR, 2005). Essa naturalização, ou banalização, de características, situações, relações, fatos ou eventos cumpre um papel fundamental na manutenção das relações de poder assimétricas, que justificam restrições, por exemplo, à presença da mulher em todos os setores sociais.

\section{$2^{\mathrm{a}}$ parte - Como as entrevistadas se veem}

a) Como ficam as relações interpessoais na família com os horários de trabalho, as agendas, os compromissos extras, como viagens e reuniões em horários não convencionais?

A maioria responde que as relações ficam comprometidas. Três delas afirmam que compartilham as tarefas com o marido/companheiro, mas apenas uma entrevistada (11A) admite que o termo "ajuda", tão largamente utilizado na divisão de tarefas domésticas, não se aplica no seu caso, uma vez que ele tem assumido o "ônus" da administração doméstica.

Há reivindicação da família quando há excesso. [...] mais cobrada. A conquista não é dividida. (1A)

Não são 100\% tranquilas. Para que seja possivel exercer o cargo, tenho que contar com a ajuda de familiares e uma boa secretária do lar. (4B)

Não há conflito. Boa estrutura familiar. Companheiro dedicado e sogra colaborativa. O marido não "ajuda”divide. (11A)

É importante observar que o fato de as mulheres trabalharem o mesmo número de horas que os homens e com as mesmas funções não significa necessariamente que tenham conseguido a sua libertação; isso pode ser uma dupla escravatura, pois, ao mesmo tempo, trabalha em sua profissão e no lar, duplicando sensivelmente a sua jornada de trabalho. 


\section{b) Em que medida você se considera uma mulher especial por estar exercendo essa função?}

Nenhuma se considera especial, e avaliam sem arrogância suas posições nos cargos como sendo decorrência de suas competências, mas as justificativas são frágeis e inconsistentes, como a menção à ocupação do mesmo cargo por outras mulheres anteriormente (7B).

Ser especial não tem relação com o gênero, mas com o profissional. (1A)

Nem um pouco especial. Tanto fazia estar no meu lugar um homem ou uma mulher. Não havia diferença entre um diretor homem ou mulher. (4B)

Outro fator para eu não me considerar especial se deve ao fato de que a função que eu atualmente ocupo já foi ocupada por duas outras mulheres anteriormente. (7B)

Não se considera especial, mas teve o mérito de ter sido valorizada. (11A)

Apenas uma delas admite ter sido "valorizada" (11A). Essa representação de atores sociais feita de forma passivada, ou seja, tornando-os impessoais, reforça o discurso de dissimulação de relações de dominação quando essas são ocultadas, negadas ou obscurecidas, por meio de escolhas sintáticas nas formas de produção discursiva, mesmo sendo repetida pela voz de quem está do lado fraco dessas relações.

\section{c) Como você é vista pelos demais integrantes de sua equipe de trabalho e como você avalia essa visão?}

Apenas três entrevistadas admitem que são consideradas autoritárias, mas essa característica é amenizada com a justificativa de que têm que se impor no cargo.

Por alguns como autoritária, centralizadora, firme. Apesar de dar liberdade de execução à equipe, quando não é feita a tarefa, tem dificuldade de chamar a atenção, e dai faz a tarefa. (2A) 
Acho que me veem como alguém um pouco bruta e um pouco rígida. Nunca parei para avaliar essa visão, não sei... (6A)

No mundo do trabalho, há a expectativa de que as mulheres sejam chefes menos exigentes, mais "boazinhas". Isso se dá em decorrência da percepção de que as mulheres são mais emocionais do que os homens. Para muitos a assertividade ainda é vista com estranhamento quando vem da parte de uma gestora, o que a faz ser considerada autoritária.

\section{d) Sua promoção ou ocupação de seu cargo já foram questionadas de alguma forma? Explique.}

A maioria diz não ter conhecimento de ter sido feito algum tipo de questionamento a suas posições, pelo menos de forma explícita. Apenas três relataram terem sido questionadas, direta ou indiretamente, por questões de gênero.

Entre os homens, que se queixam da dificuldade de serem mandados por mulher. (2A)

[...] explicitamente, na instituição de origem, por ser mulher, nova na instituição e por ser uma universidade masculina e conservadora. [...] Isso porque o cargo que ocupo é predominantemente feminino, e a educação é um lugar feminino. (11A)

A internalização da ideia de que a educação é um "lugar feminino" perpassa o discurso de praticamente todos que atuam nessa área, seja para criticar (raramente), seja para referendar (frequentemente). Nesse caso, faz-se não só menção ao gênero, do ponto de vista biológico, como também, e principalmente, no aspecto cultural demarcam-se essas diferenças entre homens e mulheres, o que, de certa forma, justifica as discriminações. Boyer (2016) ressalta esse aspecto nos relatos coletados de mulheres em posição de poder (com funções públicas), quando uma das entrevistadas (à época, Inspetora Geral da Educação Nacional e Reitora da Academia de Rouen em 2012, na França) declara: “A escola 
é minha família, minha casa, onde eu me sinto como um peixe dentro d'água" (p. 83, tradução nossa.). ${ }^{15}$

e) A mudança estrutural representada pela entrada das mulheres de diferentes classes sociais nos diversos setores do mundo do trabalho tem sido suficiente para alterar a função da mulher na sua condição social? Justifique sua resposta.

Entendemos que essa questão fica mais precisamente ilustrada por meio da Tabela 2 , em que $67 \%$ (com e sem restrição) afirmaram que a inserção das mulheres no mundo do trabalho trouxe mudanças para suas condições sociais.

TABELA 3 - Entrada das mulheres no trabalho e mudanças sociais

\begin{tabular}{c|c}
\hline Mudou & $5(42 \%)$ \\
\hline Mudou em parte & $3(25 \%)$ \\
\hline Não mudou & $4(33 \%)$ \\
\hline
\end{tabular}

Fonte: Elaborada pelas autoras.

Mudou. Ela é mais respeitada, quando tem uma formação maior. (1A)

Mudou. As mulheres estão mais livres, mais soltas, têm mais facilidade de concorrer no mercado, "ir à luta", não só para seu crescimento profissional, mas também pessoal. (4B)

Até que não mudemos a cultura arraigada em certos espíritos subservientes durante séculos, não haverá uma mudança efetiva, embora se percebam alguns progressos em relação a conquistas nos espaços de trabalho, ainda que os homens continuem a ganhar melhores salários, mesmo que tenham, no geral, menor escolaridade do que as mulheres. [As mulheres devem] assumir diferentes responsabilidades sem descuidar da familia e, nem sempre, de si mesmas. (3A)

${ }^{15}$ No original: «L'école, c'est ma famille, ma maison, j’y suis comme um poisson dans l'eau. » 
Acredito que houve alteração na condição social da mulher, sim, mas ainda não há igualdade de tratamento [...]. Por trabalhar no setor educacional, essas diferenças não aparecem tanto nos cargos exercidos por profissionais de ensino superior. (7B)

Houve um avanço, mas longe do ideal. Há o uso do termo "ajuda". A mulher tem muitas desvantagens por conta da jornada. (10A)

Não. No século XXI a mulher somou as funções, mas não dividiu. A mulher tem que se mostrar muito mais competente para ter visibilidade. Se ela der certo é porque tem características masculinas. (11A)

Não. E acho que vai demorar ainda para mudar. [...] as mulheres ainda são vistas como executoras de tarefas domésticas e familiares. (12B)

O fato de apenas $33 \%$ das entrevistadas terem admitido não ter havido mudanças efetivas para a vida das mulheres corrobora com o que tem sido largamente difundido em todos os meios quando se trata da divisão de tarefas, por exemplo.

A entrevistada $3 \mathrm{~A}$ reforça o clichê de que mulheres são capazes de fazer várias coisas ao mesmo tempo, como se isso fosse uma questão biológica, e não de divisão de tarefas impostas culturalmente pelas relações assimétricas de gênero. A advertência que faz sobre não "descuidar da família" vai na direção oposta à critica feita por Boyer (2013, p. 3) a essa visão:

Elas trabalham 365 dias por ano, ou quase isso, sem reclamarem do peso do seu trabalho ou das horas gastas no escritório, em detrimento das saídas à noite ou nos fins de semana. Quando se busca saber se certos aspectos da função valem a pena, a resposta dessas mulheres é, invariavelmente: "ao se escolher uma posição de grande 
responsabilidade, deve-se assumi-la até o fim, incluindo os seus aspectos mais difíceis." (Tradução livre) ${ }^{16}$

Essas implicações são condicionantes para determinar relações de poder vinculadas aos estereótipos de gênero, o que acaba reforçando as desigualdades entre os sexos no mercado de trabalho e contribuindo para manter a discriminação de gêneros nesse conjunto das atividades humanas.

\section{Considerações finais}

Nosso estudo foi principalmente movido pela necessidade de se analisar como as mulheres, atuando em culturas androcêntricas, contribuem para perpetuar atitudes sexistas e práticas contra elas mesmas e como alguns estudos têm contribuído para ampliar o conhecimento dessas relações, a exemplo dos desenvolvidos por Lazar (2005), Butler (2016), Scott (1995), entre outros, que embasam a teoria de gêneros aqui tratada.

Na nossa pesquisa, ficou claro que os discursos que constituem, e são constituídos, as/pelas relações sociais e as diferenças entre os sexos se manifestam por meio de construções simbólicas que determinam e mantêm o status quo, atribuindo papéis a um ou outro gênero. Em outras palavras, envolve o conjunto de expectativas sociais e padrões de comportamento distintos para homens e mulheres, que começam a se formar na menor unidade social - a família -, e continuam sendo reproduzidos, reafirmados e/ou subvertidos em outros meios, como a mídia e a publicidade (KNOLL, 2012) e nas relações de trabalho.

É importante também ressaltar que, ao mesmo tempo que muitas mulheres reforçam a assimetria de gêneros existente entre as posições de poder na sociedade, ao repetirem/confirmarem discursos discriminatórios,

\footnotetext{
${ }^{16}$ Les femmes et la haute fonction publique: interview de Bénédicte Boyer, journaliste et auteure du livre éponyme - 25/04/2013. Disponível em: <http://www.fonctionpublique.gouv.fr/fonction-publique-1135>. Acesso em: fev. 2016. No original: «Elles travaillent 365 jours par an, ou presque, sans se plaindre de la lourdeur de leur tâche ni des heures passées au bureau, au détriment des soirées ou des week-ends. Quand on cherche à savoir si certains aspects de la fonction leur coûtent, la réponse de ces femmes est invariablement: quand on choisit un poste à forte responsabilité, il faut l'assumer jusqu'au bout, y compris dans ses aspects les plus durs ».
} 
outras, como vimos neste estudo, vão tomando consciência de seu espaço na sociedade e agem criticamente em defesa de direitos iguais entre homens e mulheres. O nível de formação dessas mulheres é um dos fatores da equação que contribui para essa percepção.

Tendo em vista o que já foi exposto sobre a pesquisa, fica evidente a importância do enfoque que é dado para os discursos produzidos socialmente e a carga ideológica, hegemônica, que instaura as relações de poder presentes na sociedade e que são reveladas por meio da Análise Crítica do Discurso. É, portanto, nos diferentes discursos que se sustentam ideologias em conflito, em que se pode expressar poder ou mesmo desafio de poder.

Se as hegemonias são produzidas, reproduzidas, contestadas e transformadas no discurso, o próprio discurso apresenta-se como uma esfera da hegemonia, que depende, em parte, de sua capacidade de gerar práticas discursivas e ordens de discurso que a sustentem. Em uma concepção dialética do discurso, a contra-hegemonia tem o papel de revelar e desmistificar essas práticas discursivas, e, dessa forma, paulatinamente, fazer essas relações de poder assimétricas - como as que aqui foram identificadas sobre as mulheres exercendo cargos de poder - deixarem de se manifestar. Esse é o papel da Análise Crítica de discursos feministas.

\section{Referências}

BOYER, Bénédicte. Les femmes et la haute fonction publique. Paris: Lextenso Éditions, 2013.

BOYER, Bénédicte. (Entrevista). Disponível em: $<$ http://www.fonctionpublique.gouv.fr/fonction-publique-1135>. Acesso em: fev. 2016.

BUTLER, Judith. Problemas de gênero. 10. ed. Rio de Janeiro: Civilização Brasileira, 2016.

CHOULIARAKI, Lilie; FAIRCLOUGH, Norman. Discourse in Late Modernity: rethinking critical discourse analysis. Edinburgh: Edinburgh University Press, 1999.

COSTA, A. A. Gênero, poder e empoderamento das Mulheres. Salvador: Núcleo de Estudos Interdisciplinares sobre a Mulher - NEIM/UFBA, 2000 . 
CRENSHAW, Kimberlé. Documento para o Encontro de Especialistas em Aspectos da Discriminação Racial Relativos ao Gênero. Estudos Feministas, UFSC, v 10, n. 1, , p. 171-188, 2002. Doi: https://doi. org/10.1590/S0104-026X2002000100011

FAIRCLOUGH, Norman. Discurso e mudança social. Tradução, revisão técnica e prefácio de Izabel Magalhaes. Brasília: Editora Universidade de Brasília, 2001.

FOUCAULT, Michel. Microfísica do Poder. Organização e tradução de Robert Machado. Rio de Janeiro: Edições Graal, 1979.

GRAMSCI, Antonio. Obras Escolhidas. São Paulo: Martins Fontes, 1978.

GRAMSCI, Antonio. Concepção dialética da história. 7. ed. Rio de Janeiro: Civilização Brasileira, 1987.

HAIDAR, Julieta. El poder y la magia de la palavra. El campo del análisis del discurso. In: LUGO, Norma del Rio (Coord.). La producción textual del discurso científico. México: Universidad Autónoma Metropolitana, 2000. p. 33-65.

KNOLL, Graziela Frainer. Discursos de gênero na publicidade: análise crítica de textos publicitários em revistas. Sociais e Humanas, Santa Maria, v. 25, n. 2, p.239-252, jul./dez. 2012.

LAZAR, Michelle. Politicizing Gender in Discourse: feminist critical discourse analysis as political perspective and praxis. In: LAZAR, Michelle (Ed.). Feminist Critical Discourse Analysis: Gender, Power and Ideology in Discourse. New York: Palgrave Macmillan, 2005. p. 1-28.

MACÊDO, GOIACIRA N. S. A construção da relação de gênero no discurso de homens e mulheres, dentro do contexto organizacional. 2003. 173f. Dissertação (Mestrado em Psicologia Social) - Universidade Católica de Goiás, 2003.

MAFFESOLI, Michel. O tempo das tribos: o declínio do individualismo nas sociedades de massa. 4. ed. Rio de Janeiro: Forense Universitária, 2006.

MAFFESOLI, Michel. Quem é Michel Maffesoli: entrevistas com Christophe Bourseille. Petrópolis: De Petrus et Alii, 2011. 
MAINGUENEAU, Dominique. Doze conceitos em Análise do Discurso. Organização Sírio Possenti, Maria Cecília Perez de Souza-e-Silva; tradução Adail Sobral et al. São Paulo: Parábola Editorial, 2010.

MARTINS FERREIRA, Dina Maria. Discurso feminino e identidade social. 2. ed. São Paulo: Annablume Editora, 2009.

OLIVEIRA, Luciano Amaral (Org.). Estudos do discurso: perspectivas teóricas. São Paulo: Parábola Editorial, 2013.

RAMALHO, Viviane; RESENDE, Viviane. Análise de Discurso Crítica. São Paulo: Contexto, 2006.

RICOEUR, Paul. Hermeneutics and the Human Sciences: Essays on Language, Action and Interpretation. Ed., trans. John B. Thompson. Cambridge: Cambridge University Press, 1981. Doi: https://doi. org/10.1017/CBO9781316534984

SCOTT, Joan. Gênero: uma categoria útil de análise histórica. Educação \& Realidade, UFRGS, v. 20, n. 2, p. 71-99, jul./dez., 1995.

THOMPSON, John B. Ideology and Modern Culture. Cambridge: Polity Press, 1990.

VAN DIJK, Teun A. Discurso e poder. São Paulo: Contexto, 2008.

WODAK, Ruth. Do que trata a $\mathrm{ACD}$ - um resumo de sua história, conceitos importantes e seus desenvolvimentos. Linguagem em (Dis)curso, Tubarão, v. 4, n. esp., p. 223-243, 2004.

WODAK, Ruth. Gender mainstreaming and the European Union: interdisciplinarity, gender studies and CDA. In: LAZAR, Michelle (Ed.). Feminist Critical Discourse Analysis: Gender, Power and Ideology in Discourse. New York: Palgrave Macmillan, 2005. p. 90-113. 